\title{
Response of the Fetal and Newborn Lamb to Glucose and Tolbutamide Infusions
}

\author{
ANTHONY F. PHILIPPS (32), JOSEPH W. DUBIN, AND JOHN R. RAYE \\ Department of Pediatrics, Division of Neonatology, The University of Connecticut Health Center, Farmington, \\ Connecticut, USA
}

\begin{abstract}
Summary
Tolbutamide infused into the chronically catheterized sheep fetus produced significant secretion of insulin. An optimal dose range of $100-200 \mathrm{mg} / \mathrm{kg}$ estimated fetal weight was demonstrated. Paired tolbutamide and glucose infusions using a square wave technique demonstrated that although early phase insulin secretion is diminished in the fetus, this is not due to an absolute deficiency of stored insulin. Tolbutamide produced peak insulin concentrations of $51.6 \pm 9.0 \mu \mathrm{u} / \mathrm{ml}$ by $20 \mathrm{~min}$ postinfusion in the fetus. When similar tolbutamide infusions were performed in neonatal lambs, qualitatively similar insulin response curves were demonstrated although peak insulin levels were much greater $(260 \pm 70$ $\mu \mathrm{u} / \mathrm{ml}$ at $20 \mathrm{~min}$ ).

A fall in plasma glucose was demonstrated in both fetal and neonatal lambs (to 75 and $39 \%$ of control values, respectively) by $60 \mathrm{~min}$ after tolbutamide infusion. In the fetus, this fall was not associated with changes in maternal glucose concentration.
\end{abstract}

\section{Speculation}

The maturation of early phase insulin secretion in the neonate may involve a variety of factors beyond simple storage of insulin. The ability of the neonate to respond briskly to alterations in plasma glucose may be highly significant in an adaptation to "feast-fast" conditions. The hypoglycemia produced in response to endogenously secreted insulin in the fetus and neonate is consistent with insulin's role in accelerating glucose uptake and utilization.

Insulin has been identified in pancreatic islets of a number of mammalian species relatively early in gestation (24). Willes et al. (28) and Sodoyez-Goffaux et al. (27) have demonstrated increasing insulin storage in fetal pancreatic tissue proportional to gestational age. In the adult, secretion of insulin in response to a constant glucose stimulus occurs in a biphasic mode with early and late peaks (8). Recently, Blazquez et al. (3) and Philipps et al. (23) have shown an absence or diminution in the early phase of insulin secretion in response to fetal glucose elevation. Yet the newborn lamb and other species of newborns exhibit relatively brisk biphasic insulin responses during glucose infusion shortly after birth $(1,18)$.

Tolbutamide is a well known insulin secretogogue that appears to release stored insulin from the $\beta$ cell by a mechanism different from that of glucose $(10,15)$ although a final common pathway of elevation of cyclic adenosine 3', 5'-monophosphate (c-AMP) has been implicated (11). Tolbutamide has been used in vivo and in vitro fetal preparations with conflicting results $(9,20,27)$. It is reported to have few side effects on peripheral tissues (16), although these effects have not been extensively studied in the fetus and neonate.

Tolbutamide was infused into chronically catheterized fetal and neonatal sheep to determine whether or not fetal reactivity to this sulfonyl urea does exist in vivo, and if so, to determine whether or not fetal insulin is stored in sufficient quantities to allow early release. The fetal metabolic response to endogenous insulin secretion was observed under these conditions.

\section{METHODS}

Seven pregnant ewes between 110-135 days of gestation (term gestation in the sheep is 147 days) were studied. IV sodium pentobarbital and spinal anesthesia (15 mg pontocaine) were administered preoperatively. Indwelling polyvinyl chloride catheters were inserted into a fetal pedal artery and vein, into the maternal femoral artery, and then tunneled subcutaneously to the mother's flank. Postoperative care and feeding were performed as previously described (12). Experiments were not performed until after a 4-5 day recovery period when the animals were being fed ad libitum.

\section{TOLBUTAMIDE DOSE RESPONSE}

Varying doses of tolbutamide were infused into two fetal lambs not utilized in subsequent experiments. Tolbutamide (29) was infused via the fetal venous catheter in doses of $50,100,200,300$, and $400 \mathrm{mg} / \mathrm{kg}$ estimated fetal weight. Tolbutamide was dissolved in normal saline such that all infusions were accomplished at a volume of $10 \mathrm{ml}$ given slowly by hand over $60 \mathrm{sec}$. Serial infusions were performed only after a recovery period of at least $48 \mathrm{hr}$ after the last infusion. Plasma arterial samples for glucose and insulin were obtained twice in the 30 min preceding infusion and then at $1 \frac{1}{2}, 3,5,10,20,30,60,90$, and $120 \mathrm{~min}$ postinfusion. Maternal arterial glucose and insulin samples were obtained during the control period and at 30,60 , and $120 \mathrm{~min}$ postinfusion to assess possible changes in maternal homeostasis.

\section{FETAL GLUCOSE INFUSION}

Five pregnant ewes between 110-135 days of gestation were studied. Glucose was infused into the fetal venous catheter to produce an instantaneous elevation in fetal plasma glucose to 50 $\mathrm{mg} / \mathrm{dl}$ above control values. A loading dose of $10 \%$ sterile glucose in water was given over $1 \mathrm{~min}$ via syringe pump followed by a constant infusion for $60 \mathrm{~min}$. The dosage of glucose was calculated as previously reported (23). Control fetal samples for plasma arterial glucose and insulin were obtained twice in the $30 \mathrm{~min}$ preceding infusion and at $1 \frac{1}{2}, 3,5,10,20,30$, and 60 min during infusion. A total of nine infusions were performed at gestational ages 120-140 days (Table 1). Maternal glucose and insulin samples were obtained as in the tolbutamide dose response experiments.

\section{FETAL TOLBUTAMIDE INFUSION}

Tolbutamide was infused as in the dose response experiments at a dose of $200 \mathrm{mg} / \mathrm{kg}$ estimated fetal weight. Each tolbutamide infusion was paired to a glucose infusion which had been performed between 24-96 hr previously. Therefore, a total of nine paired infusions were performed in five fetal lambs. Fetal and 
Table 1. Characteristics of surgical preparations and outcome

\begin{tabular}{|c|c|c|c|c|c|c|}
\hline \multirow[b]{2}{*}{ Animal \# } & \multirow{2}{*}{$\begin{array}{l}\text { Gestational } \\
\text { age at surgery } \\
\text { (days) }\end{array}$} & \multirow{2}{*}{$\begin{array}{l}\text { Length of } \\
\text { preparation } \\
\text { (days) }\end{array}$} & \multicolumn{2}{|c|}{ Gestational age at time of infusion (days) } & \multirow{2}{*}{$\begin{array}{l}\text { Single or } \\
\text { twin }\end{array}$} & \multirow[b]{2}{*}{ Outcome } \\
\hline & & & Glucose & Tolbutamide' & & \\
\hline 4 & 114 & 11 & 120 & 124 & $\mathbf{S}$ & $\begin{array}{l}\text { Aborted, } 134 \text { days, } 10 \text { days after last } \\
\text { experiment }\end{array}$ \\
\hline \multirow[t]{2}{*}{6} & 130 & 9 & 135 & 136 & $\mathbf{S}$ & Delivered, live born \\
\hline & & & 137 & 139 & & \\
\hline \multirow[t]{2}{*}{7} & 132 & 8 & 136 & 137 & $\mathbf{S}$ & Delivered, live born \\
\hline & & & 139 & 140 & & \\
\hline \multirow[t]{2}{*}{10} & 121 & 25 & 126 & 127 & $T$ & Delivered, live born twins \\
\hline & & & 131 & 133 & & \\
\hline 14 & & & 138 & 139 & & \\
\hline \multirow[t]{5}{*}{16} & $\begin{array}{l}121 \\
126\end{array}$ & 19 & 131 & 133 & $\mathbf{S}$ & Delivered, live born \\
\hline & 126 & 20 & & $\begin{array}{l}134(50 \mathrm{mg} / \mathrm{kg}) \\
136(100)\end{array}$ & $\mathbf{S}$ & $\begin{array}{l}\text { Aborted, } 147 \text { days, intrapartum death } \\
24 \mathrm{hr} \text { after last experiment }\end{array}$ \\
\hline & & & & $140(200)$ & & \\
\hline & & & & $142(300)$ & & \\
\hline & & & & $146(400)$ & & \\
\hline \multirow[t]{4}{*}{17} & 118 & 13 & & $123(50 \mathrm{mg} / \mathrm{kg})$ & $\mathbf{S}$ & Intrapartum death at 150 days, 20 days \\
\hline & & & & $125(100)$ & & after last infusion \\
\hline & & & & $129(200)$ & & \\
\hline & & & & $131(300)$ & & \\
\hline
\end{tabular}

\footnotetext{
${ }^{\prime} 200 \mathrm{mg} / \mathrm{kg}$ estimated fetal weight unless otherwise specified.
}

maternal blood specimens for glucose and insulin were obtained as in the tolbutamide dose response experiments.

\section{LAMB TOLBUTAMIDE INFUSION}

Four healthy newborn lambs from the fetal preparations above were operated on within $24 \mathrm{hr}$ after birth. Femoral venous and arterial catheters were placed after local xylocaine $(1 \%)$ anesthesia. Venous infusions were performed between 2-5 days of age. No attempt was made to control the time of feeding before infusion. Tolbutamide at a dose of $100 \mathrm{mg} / \mathrm{kg}$ of body weight was infused over $1 \mathrm{~min}$. Blood for plasma glucose and insulin was withdrawn as in the previous tolbutamide infusions via femoral artery catheter.

\section{BIOCHEMICAL STUDIES}

Blood samples for glucose determinations were withdrawn and transferred to EDTA-coated tubes and then centrifuged for $5 \mathrm{~min}$. Plasma was withdrawn and measured within $30 \mathrm{~min}$ of sampling utilizing the glucose analyzer glucose oxidase method (30). Blood samples for insulin were withdrawn and placed in chilled polyethylene tubes each containing 10 units of heparin. These were centrifuged, the plasma withdrawn, and the samples stored at -20 $\mathrm{C}$ until time of analysis. Insulin was measured by radioimmunoassay using a modification $(23,31)$ of the method of Morgan and Lazarow (21). Each assay consisted of all samples from one animal in order to avoid interassay variability.

\section{STATISTICAL METHODS}

Results are expressed as mean \pm SEM. Statistical significance was assessed with the paired Student's $t$ test.

\section{RESULTS}

A typical tolbutamide dose response curve in the fetal sheep is shown in Figure 1. Brisk elevations in plasma insulin were seen with the maximum response noted between $100-200 \mathrm{mg} / \mathrm{kg}$ estimated fetal weight. A dose of $300 \mathrm{mg} / \mathrm{kg}$ yielded a quantitatively lower response with a relatively long latent period. One infusion (Table 1) of $400 \mathrm{mg} / \mathrm{kg}$ yielded no insulin response and may have contributed to fetal demise $24 \mathrm{hr}$ postinfusion.

The pooled results of the nine paired fetal glucose and tolbutamide infusions are presented in Figures 2 and 3 . Glucose infusion produced a rough square wave with elevation in plasma glucose to about $40 \mathrm{mg} / \mathrm{dl}$ above baseline values (Figure 2).

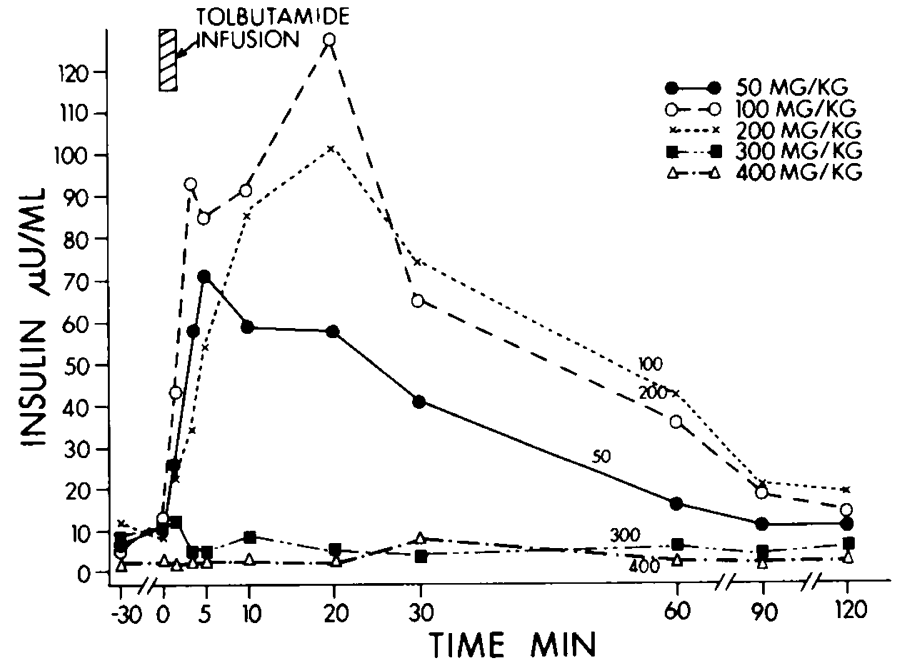

Fig. 1. Insulin response of one fetal lamb to varying doses of iv administered tolbutamide.

Plasma insulin concentration rose significantly only after $5 \mathrm{~min}$ of infusion $(P<0.01)$ but peak values $(54.4 \pm 9.6 \mu \mathrm{u} / \mathrm{ml})$ were not obtained until 20-30 min of infusion. Mean peak insulin concentration was approximately three times the control value.

The insulin response to fetal tolbutamide infusion was more rapid, a significant elevation $(P<0.02)$ being demonstrated by $1 \frac{1}{2}$ min postinfusion (Figure 3 ). Peak insulin concentrations were achieved by 20 min postinfusion (mean peak concentrations of $51.6 \pm 9.0 \mu \mathrm{u} / \mathrm{ml}$ ), and were similar to those in the glucose infusion experiments. The plasma insulin concentration remained significantly elevated until 120 min postinfusion when values had returned to baseline. No relationship was found between fetal gestational age at time of infusion and peak insulin concentration achieved. Baseline fetal arterial blood gases were performed in five out of the seven animal preparations before and after tolbutamide infusion. Results were consistently in the normal range, implying normal fetal oxygenation.

Changes in plasma glucose during tolbutamide infusion were assessed at 30 and $60 \mathrm{~min}$ in each maternal-fetal pair. Although no consistent changes in maternal glucose concentration occurred, fetal plasma glucose fell $2.6 \pm 0.9 \mathrm{mg} / \mathrm{dl}$ from control values by $30 \mathrm{~min}$ of infusion $(P<0.05)$ and $5.1 \pm 1.2 \mathrm{mg} / \mathrm{dl}$ by $60 \mathrm{~min}$ of infusion $(P<0.01)$. This represents a $25 \%$ reduction in fetal 
plasma glucose concentration after tolbutamide infusion. When these results were subjected to paired $t$ test analysis to assess the effect of individual changes in maternal glucose concentration on each individual fetal-maternal pair, no such effect was found $(P$ $>0.1$ ). No correlation was found between the fall in fetal glucose and peak fetal insulin levels achieved.

Figure 4 depicts the response of the four neonatal lambs to tolbutamide infusion. As in the fetal infusions, a brisk rise in plasma insulin was noted by $1 \frac{1 / 2}{2}$ min postinfusion. Peak insulin levels, however, were higher and somewhat more variable, being achieved by $10-30$ min postinfusion (maximum concentration $=$ $260 \pm 70 \mu \mathrm{u} / \mathrm{ml}$ at $20 \mathrm{~min}$ ). No correlation was found between initial plasma glucose concentration and peak insulin level achieved. The plasma glucose response was similar to those in the fetal experiments but more exaggerated. Plasma glucose fell to $39 \%$ of control values by $60 \mathrm{~min}(P<0.001)(\Delta$ glucose $=66.3 \pm$ $7.6 \mathrm{mg} / \mathrm{dl}$ ) and had not returned to baseline by the end of the study period.

\section{DISCUSSION}

Previously reported work concerning the ability of fetal pancreatic tissue to respond to insulin secretogogues such as the sulfonylureas has been conflicting. Results utilizing incubated

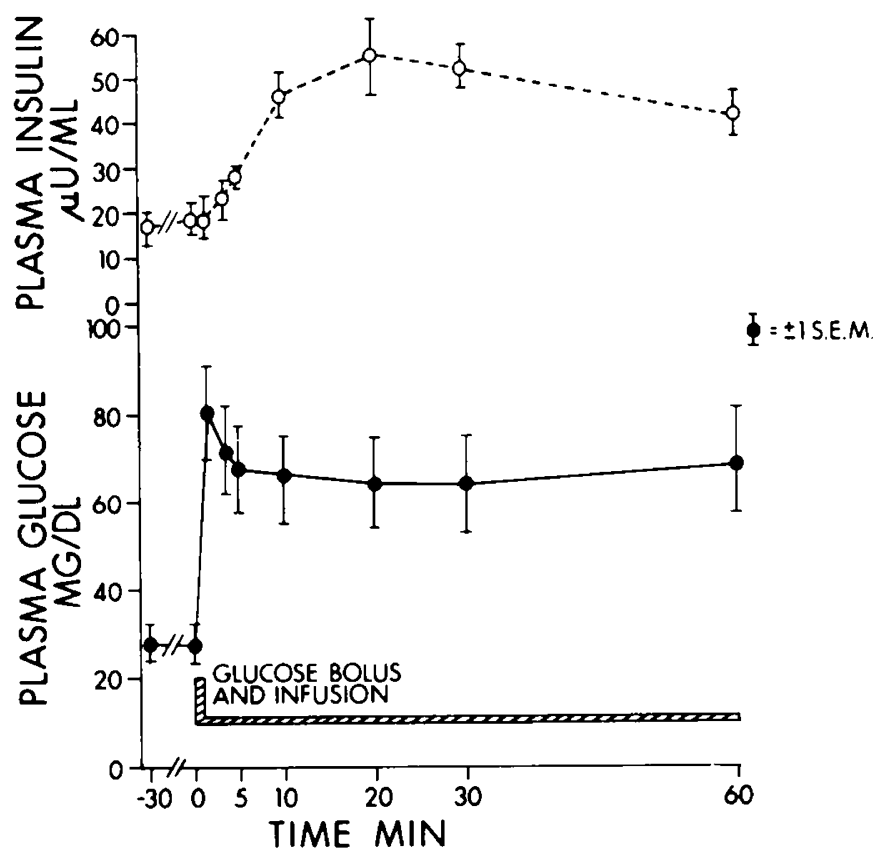

Fig. 2. Fetal insulin response to glucose infusion (nine infusions in five animals).

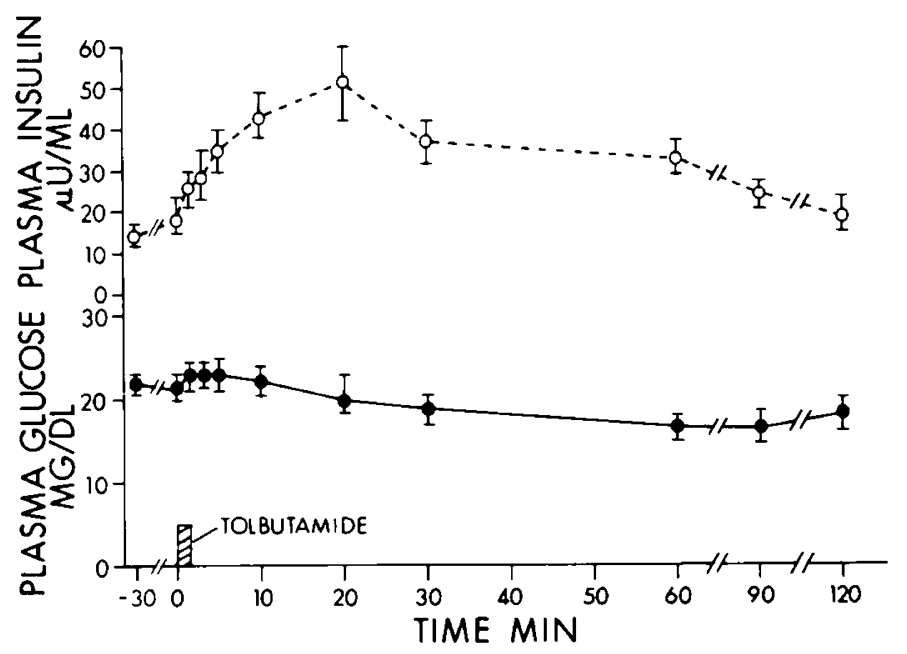

Fig. 3. Fetal insulin and glucose response to fetal tolbutamide infusion of $200 \mathrm{mg} / \mathrm{kg}$ (nine infusions in five animals). Bars represent \pm 1 SEM.

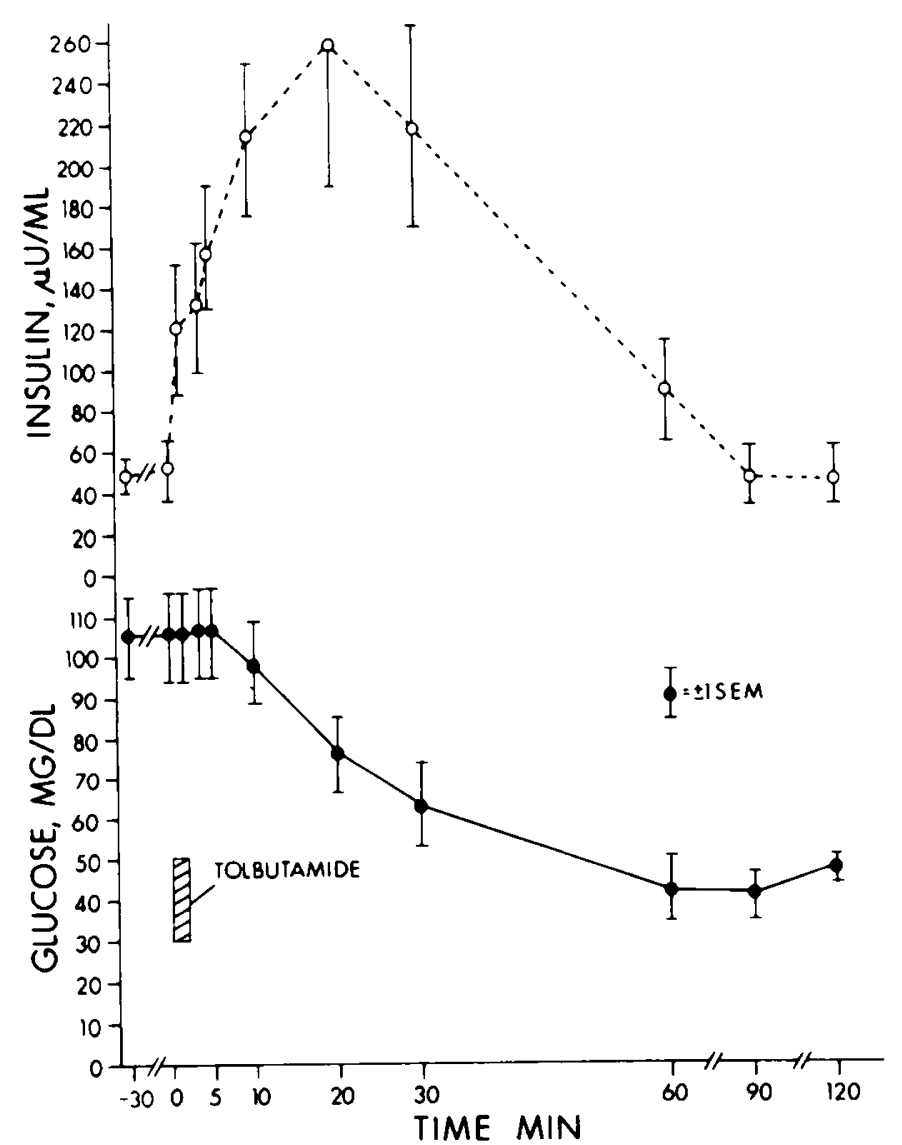

Fig. 4. Insulin and glucose response to tolbutamide infusion (100 mg/ $\mathrm{kg}$ ) in the newborn lamb.

fetal human (9) or rat (27) pancreas demonstrated no significant insulin release in response to tolbutamide. Yet Lambert et al. (14) using an in vitro fetal rat preparation demonstrated significant insulin release in response to the addition of tolbutamide to the culture medium. Mintz et al. (20) using the catheterized fetal rhesus monkey noted elevations of fetal insulin in two out of three fetuses receiving tolbutamide.

In the present study, tolbutamide was infused into the chronically catheterized fetal lamb and caused significant elevations in plasma insulin in all animals studied. The fetal dose response curve was qualitatively similar to those reported in the adult human (10) and rat (15) in that an optimal dose range exists, above which no further increment in insulin response can be seen. Likewise, a characteristic lag time before peak elevation in insulin concentration was demonstrated in both the fetal and neonatal lamb.

The typical biphasic insulin response to glucose infusion (8) is diminished in the sheep fetus but appears within several days after birth (23). Tolbutamide was chosen to investigate this basic difference between the fetus and neonatal lamb. Tolbutamide acts primarily on the early phase of insulin secretion by releasing stored insulin (8). The mechanism for induction of secretion has recently been demonstrated to be intimately associated with elevation of intracellular c-AMP in the pancreatic islet (5). In this respect, it is similar in mechanism of action to that of glucose on the $\beta$ cell (11). Tolbutamide inhibits islet phosphodiesterase activity (5) and may also stimulate the activity of adenylcyclase (13). However, the insulin secretory response after tolbutamide differs from glucose in being monophasic and in having a different latent period before secretion (15). Unlike glucose, it has been demonstrated that tolbutamide does not induce insulin synthesis (15) and no second phase is seen with tolbutamide even though intracellular c-AMP levels remain elevated.

The rapid elevation in fetal plasma insulin after tolbutamide implies significant availability of stored insulin. It, therefore, is unlikely that an absolute deficiency of stored insulin can account 
for the failure of early insulin release in response to fetal glucose infusion. Paired glucose and tolbutamide infusions were undertaken to avoid the possibility that tolbutamide might induce lasting change in the kinetics of fetal insulin secretion. No such induction was demonstrated when glucose infusions were repeated after tolbutamide.

One possible explanation for the relative diminution in early phase insulin secretion after glucose infusions might be the relatively lower blood sugar of the fetal lamb as compared with the neonate. Bassett et al. (2) have demonstrated in vitro that fetal lamb pancreas exhibits a sigmoidal dose response curve similar to those of other species $(25)$ when incubated in varying concentrations of glucose. This response was maximal at $100 \mathrm{mg} / \mathrm{dl}$ glucose concentration. However, when fetal glucose infusions were performed in three fetal lambs designed to elevate plasma glucose to levels in excess of $100 \mathrm{mg} / \mathrm{dl}$ (range $100-150 \mathrm{mg} / \mathrm{dl}$ ), no early phase could be demonstrated. Peak insulin values, however, were substantially above those where lesser concentrations of glucose were achieved.

Infusions of tolbutamide into the neonatal lamb demonstrated qualitatively similar insulin response curves as those in the intrauterine experiments. Although the peak insulin concentrations achieved were five-fold higher in the neonatal lambs, blood glucose was also considerably higher. Likewise, tolbutamide concentrations were not measured and, thus, no statement can be made regarding quantitative changes in insulin secretion after fetal $v s$. neonatal tolbutamide infusions. However, although the fetal pancreatic response to glucose infusion is characterized by its lack of brisk release of stored insulin, the responses of the fetus and neonate to tolbutamide are quite similar. Because both glucose and tolbutamide-induced insulin secretion utilize a common biochemical pathway with elevations of islet c-AMP and influx of calcium, other more basic changes must be invoked to explain the appearance of early phase insulin secretion in response to glucose after birth. Possible factors such as islet cell receptor changes (22), intracellular calcium flux (17), islet electrical activity (19), proinsulin content or the influence of gastrointestinal hormones after feeding should be considered.

Endogenous insulin secretion in the fetal and neonatal lamb was associated with a characteristic fall in plasma glucose between 30 and $60 \mathrm{~min}$ after initial elevation of insulin levels. Although, in the steady state, there is a linear relationship between fetal and maternal blood glucose (7), the fall in fetal plasma glucose after tolbutamide infusion was entirely independent of changes in maternal glucose concentration. Pharmacologic doses of exogenous insulin have been shown to cause hypoglycemia (6) and to increase glucose utilization (26) when infused into the fetal lamb. A recent study (4) suggests some correlation between fetal glucose utilization and plasma insulin concentration when more physiologic concentrations $(<100 \mu \mathrm{u} / \mathrm{ml})$ of insulin were achieved with infusion.

No direct evidence for a fetal metabolic response to endogenous insulin secretion, however, is presently available. Although no statement can be made regarding a quantitative measurement of fetal glucose uptake after tolbutamide, the time course of the consequent hypoglycemia suggests that endogenous insulin secretion is the causative factor.

\section{REFERENCES AND NOTES}

I. Asplund, $K$.: The effect of glucose on the insulin secretion in foetal and newborn rats, In: S. Falkmer, B. Hellman, and I. B. Taljedal: The Structure and Metabolism of the Pancreatic Islets, pp. 477-484 (Pergamon Press, London. 1970).

2. Bassett, J. M., Madill, D.. Nicol, D. H., and Thorburn, G. D.: Further studies on the regulation of insulin release in foetal and post-natal lambs: The role of glucose as a physiological regulator of insulin release in utero. In: Foetal and
Neonatal Physiology, Proceedings of the Sir Joseph Barcroft Centenary Symposium. pp. 351-359 (Cambridge University Press, London, 1973).

3. Blazquez, E., Lipshaw, L. A., Blazquez. M., and Foa, P. P.: The synthesis and release of insulin in fetal, nursing and young adult rats: Studies in vivo and in vitro. Pediatr. Res., 9: 17 (1975).

4. Carson, B. S., Philipps, A. F., Simmons, M. A., Battaglia, F. C., and Meschia, G. Effects of a sustained fetal insulin infusion upon glucose uptake and oxygenation. Program, 1978. 25th Meeting of the Society for Gynecological Investigation, Atlanta, Georgia. (Abstract) p. 83.

5. Charles, M. A., Lawecki, J., Steiner, A. L., and Grodsky, G. M.: Cyclic nucleotides in pancreatic islets: tolbutamide- and arginine-induced insulin release. Diabetes, 25: 256 (1976).

6. Colwill, J. R., Davis, J. R., Meschia, G., Makowski, E. L., Beck, P., and Battaglia, F. C.: Insulin-induced hypoglycemia in the ovine fetus in utero. Endocrinology, 87: $710(1970)$.

7. Comline, R. S. and Silver, M.: Daily changes in foetal and maternal blood of conscious pregnant ewes, with catheters in umbilical and uterine vessels. J. Physiol., 209: 567 (1970).

8. Curry, D. L., Bennett, L. L., and Grodsky, G. M.: Dynamics of insulin secretion by the perfused rat pancreas. Endocrinology, 83: 572 (1968).

9. Espinosa de los Monteros, A., Driscoll. S. G., and Steinke, J.: Insulin release from isolated human fetal pancreatic islets. Science, I68: 1111 (1970).

10. Ganda, O. P., Kahn. C. B., Soeldner, J. S., and Gleason. R. E.: Dynamics of tolbutamide. glucose, and insulin interrelationships following varying doses of intravenous tolbutamide in normal subjects. Diabetes, 24: 354 (1975).

11. Grill. V., and Cerasi, E.: Interacting effects of sulfonylureas and glucose on cyclic AMP metabolism and insulin release in pancreatic islets of the rat. $J$. Clin Invest., 61: 1346 (1978).

12. James, E. J., Raye, J. R., Gresham, E. L., Makowski, E. L., Meschia, G., and Battaglia, F. C.: Fetal oxygen consumption, carbon dioxide production, and glucose uptake in a chronic sheep preparation. Pediatrics, 50: 361 (1972).

13. Kuo, W. N.. Hodgins, D. S., and Kuo, J. F.: Adenylate cyclase in Islets of Langerhans. J. Biol. Chem., 248: 2705 (1973).

14. Lambert, A. E., Jeanrenaud, B., Junod, A., and Renold, A. E.: Organ culture of fetal rat pancreas. II. Insulin release induced by amino and organic acids, by hormonal peptides, by cationic alterations of the medium and by other agents. Biochim. Biophys. Acta, 174: 540 (1969).

15. Lenzen, S.: The immediate insulin-secretory response of the rat pancreas to glucose compared with tolbutamide and other secretagogues. Diabetes, 27: 27 (1978).

16. Levy, G. S. The effects of sulfonylureas on peripheral metabolic processes. Fed. Proc., 36: 2720 (1977).

17. Malaisse, W. J.: Insulin secretion-multi-factorial regulation for a single process of release. Diabetologia, 9: 167 (1973)

18. Manns, J. G., and Boda, J. M.: Insulin release by acetate, propionate, butyrate, and glucose in lambs and adult sheep. Am. J. Physiol., 211: 747 (1967).

19. Meissner, H. R.: Electrophysiological evidence for coupling between $\beta$ cells of pancreatic islets. Nature, 262: 502 (1976).

20. Mintz, D. H., Chez, R. A., and Horger, E. O.: Fetal insulin and growth hormone metabolism in the subhuman primate. J. Clin. Invest.. 48: 176 (1969).

21. Morgan, C. R. and Lazarow, A.: Immunoassay of insulin - two antibody system. Diabetes, 12: 115 (1963)

22. Permutt, M. A., and Kipnis, D. M.: Insulin biosynthesis and secretion. Fed. Proc., 34: 1549 (1975).

23. Philipps, A. F Carson, B. S., Meschia, G., and Battaglia, F. C.: Insulin secretion in fetal and newborn sheep. Am. J. Physiol., 235: E467 (1978).

24. Pictet, R. and Rutter, W. J.: Development of the embryonic endocrine pancreas. In: Steiner, D. F. and Freinkel, N.: Handbook of Physiology, Section 7. Endocrinology Volume I. Endocrine pancreas. pp. 25-66 (American Physiological Society, Washington, D.C., 1972).

25. Pipeleers, D. G., Marichal, M., and Malaisse, W. J.: The stimulus-secretion coupling of glucose-induced insulin release. XIV. Glucose regulation of insulin biosynthetic activity. Endocrinology, 93: 1001 (1973).

26. Simmons, M. A., Jones, M. D., Jr., Battaglia, F. C., and Meschia. G.: Insulin effect on fetal glucose utilization. Pediatr. Res., 12: 90 (1978)

27. Sodoyez-Goffaux, F., Sodoyez, J. C., and Foa, P. P.: Effects of gestational age. birth and feeding on the insulinogenic response to glucose and tolbutamide by fetal and newborn rat pancreas. Diabetes, 20: 586 (1971).

28. Willes, R. F., Boda, J. M., and Stokes, H.: Cytological localization of insulin and insulin concentration in the fetal ovine pancreas. Endocrinology, 84: 671 (1969).

29. Orinase, Upjohn Laboratories, Kalamazoo, Michigan.

30. Beckman Instruments, Palo Alto, California.

31. Ovine insulin standards were kindly supplied by Mary Root. Ph.D.. Eli Lilly Research Laboratory, Indianapolis, Indiana.

32. This research was supported by a grant from The Charles H. Hood Foundation.

33. Requests for reprints should be addressed to: A. F. Philipps, M.D. University of Connecticut Health Center, Department of Pediatrics. Farmington, Connecticut, 06032 (USA)

34. Received for publication October 17, 1978.

35. Accepted for publication January 23, 1979. 